\title{
Corpo Editorial
}

\section{Camila Gouvea Prates de Paiva}

Doutoranda em Letras pela Universidade Estadual de Londrina (UEL). Triagem/Revisão Textual.

\section{Christie Akemi Mariano Sakamoto}

Graduanda em Letras Vernáculas pela Universidade Estadual de Londrina (UEL). Revisão Textual.

\section{Danilo Pontes Rodrigues}

Mestre em História pela Universidade Estadual de Londrina (UEL). Triagem.

\section{Eloyr Doin Pacheco}

Graduado em História pela Universidade Norte do Paraná (UNOPAR). Técnico.

\section{Giovanna Trevelin}

Mestranda em História Social pela Universidade Estadual de Londrina (UEL). Chek-List/ABNT.

\section{Ingrid Batista Marques}

Graduanda em História pela Universidade Estadual de Londrina (UEL). Triagem.

\section{José Rodolfo Vieira}

Doutorando em História e Sociedade pela Universidade Estadual Paulista (UNESP). Editor Adjunto.

\section{Lara Guilherme}

Graduanda em Letras Vernáculas pela Universidade Estadual de Londrina (UEL). Revisão Textual.

\section{Laura Tejada Vergara}

Graduanda em Design Gráfico pela Universidade Estadual de Londrina (UEL). Diagramação.

\section{Lunielle de Brito Santos Bueno}

Mestranda em História Social e graduanda em Filosofia pela Universidade Estadual de Londrina (UEL). Marketing/Relações Públicas e Leitura de Prova. 


\section{Marina dos Santos Galli}

Mestranda em História Social pela Universidade Estadual de Londrina (UEL). Designer.

\section{Mariana Furio da Costa}

Doutoranda em Estudos da Linguagem pela Universidade Estadual de Londrina (UEL). Revisora de língua inglesa.

\section{Priscila Rosalen Pasetto de Almeida}

Mestra em História pela Universidade Estadual de Londrina (UEL). Revisora de língua francesa.

\section{Richard Gonçalves André}

Pós-Doutor em Língua, Literatura e Cultura Japonesa pela Universidade de São Paulo (USP) Professor do Departamento de História da Universidade Estadual de Londrina (UEL). Editor Chefe. 